\title{
Response Surface Optimization for the Extraction of Antioxidant and Total Tannins from Geum Japonicum
}

\author{
Riyadh A.S. Thabit, Xiang-Rong Cheng, Nabil AL-hajj, Hua-Wei Shi, Xue Tang, Guo-Wei Le* \\ State Key Laboratory of Food Science and Technology, School of Food Science and Technology, Jiangnan University, Wuxi, China \\ *Corresponding author: Igw@jiangnan.edu.cn
}

Received May 03, 2014; Revised June 03, 2014; Accepted June 09, 2014

\begin{abstract}
This study aims to determine the best extraction conditions and find out the effects of solvent type (ethanol, aceton, and ionic liquid (1-butyl-3-methylimidazolium bromide) [BMIM] Br), time (20-60 min), and microwave power (200-600 w) on antioxidant activity and total tannins (TT) of Geum japonicum. The three parameters, type solvents, extraction time and microwave power, were optimized using the Boxe Behnken design (BBD) with a quadratic regression model built by using response surface methodology (RSM). The experiments were carried out according to 17 runs with 3 variables and 3 levels for the optimization. The extracts were analyzed by spectrophotometeric methods for the antioxidant and (TT). The optimal extraction conditions were determined as follows: [BMIM]Br), microwave power $437.07 \mathrm{w}$, extraction time $36.89 \mathrm{~min}$ for the best antioxidant $92.24 \%$ and TT $2.44 \mathrm{mg} \mathrm{GAE} / \mathrm{g}$ in these conditions. While the experimental maximum antioxidant was $91.5 \pm 2.12$ and TT was 2.72 $\pm 2.34 \mathrm{mg} \mathrm{GAE} / \mathrm{g}$ of the G. japonicum extract, which matched with the predicted values. Results showed that [BMIM] [Br] solvent are more efficient in the extraction of antioxidant and TT compare with ethanol and aceton solvents. This study confirmed that the [BMIM] [Br], time $36.89 \mathrm{~min}$ and power $437.07 \mathrm{w}$ were the most efficient for extraction of antioxidant and TT.
\end{abstract}

Keywords: response surface methodology, microwave, [BMIM] [Br], Geum japonicum, antioxidant, total tannins

Cite This Article: Riyadh A.S. Thabit, Xiang-Rong Cheng, Nabil AL-hajj, Hua-Wei Shi, Xue Tang, and Guo-Wei Le, "Response Surface Optimization for the Extraction of Antioxidant and Total Tannins from Geum Japonicum.” Journal of Food and Nutrition Research, vol. 2, no. 6 (2014): 270-276. doi: 10.12691/jfnr-2-6-1.

\section{Introduction}

Many natural products and their components have been used as traditional medicines, dietary supplements, and functional foods. Recently, their efficacy and safety for humans have been undergoing scientific evaluation worldwide. Thus, verification of antiviral activities of natural products and identification of their active components would demonstrate that they possess biological activity and safety for humans. Such active components may become reliable markers in the quality control of traditional medicines, dietary supplements, and functional foods [1].

The genus Geum (Rosaceae family) comprises ca. 70 species of plants, four of which are found in China. Geum japonicum, which is abundant in China and commonly known as "Lanbuzheng", has been used as a herbal medicine in diuretics and astringents in traditional Chinese medicine [2]. It is also used for the treatment of dizziness and headache in some regions of China [3]. The previous phytochemical studies on the constituents of Geum japonicum THUNB. (Rosaceae) led to the discovery of many compounds, including triterpenoids and tannins [4].

RSM is a one of mathematical and statistical techniques used to identify for optimum conditions of factors for desirable responses; it evaluates the relative significance of several treatment factors even in the presence of complex interactions. The design leads to the generation of contour plots by linear or quadratic effects of the key variables, and a model equation is derived that fits the experimental data to calculate the optimal response of the system [5].

The current study was aimed to employ response surface methodology to study the effects of microwave power, extraction time, and solvents to determine the best extraction conditions for Geum japonicum, in order to maximize simultaneously the yield of antioxidant and TT by using response surface methodology.

\section{Material and Methods}

\subsection{Chemicals and Machine}

Folin-Ciocalteu reagent, gallic acid, quercetin reagent, vanillin-glacial and perchloric acid were from Sigma (USA) and D-101 macroporous resin was from Tianjin Dajun Co., Ltd. While ethanol, was from Sinopharm chemical regent co. ltd. Spectrophotometer (ShanghaiTechcomp, UV 2300), balance (Shanghai-Mettle Toledo, AB 204-N), rotary evaporator (Shanghai-Biochemical Equipment), water bath (Shanghai-Hengzi) and Microwave (Beijing- Xianghu Science \& Technology. XH-200A). 


\subsection{Preparation of (1-Butyl-3- Methylimidazolium Bromide) [BMIM] [Br].}

Prepared the $1.5 \mathrm{M}$ [BMIM] [Br] according to the following equation under the Condition $400 \mathrm{~W}, 120{ }^{\circ} \mathrm{C}$ and 20 min by microwave.

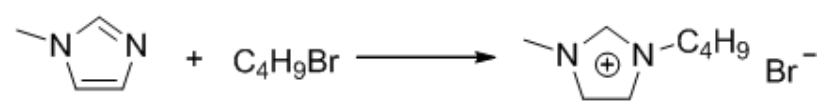

${ }^{1} \mathrm{H}-\mathrm{NMR}: 8.73$ (1H, s), $7.50(1 \mathrm{H}, \mathrm{d}, J=2.4 \mathrm{~Hz}), 7.46$ $(1 \mathrm{H}, \mathrm{d}, J=2.4 \mathrm{~Hz}), 4.22(2 \mathrm{H}, \mathrm{t}, J=9.6 \mathrm{~Hz}), 3.91(3 \mathrm{H}, \mathrm{s})$, 1.87 (2H, m), 1.34 (2H, m), 0.95 (3H, s, $J=10.0 \mathrm{~Hz})$.

\subsection{Plant Materials}

The whole parts of $G$. japonicum were bought from Beijing Tong Ren Tang, P.R. China, in July 2012. was deposited at the School of Food Science and Technology, Jiangnan University, Wuxi, P. R. China.

\subsection{Preparation of Extracts Using Microwave-Assisted Extraction (MAE)}

The G. japonicum was air-dried in shade, 5 grams from plant was extracted with $150 \mathrm{ml}$ of $1.5 \mathrm{M}$ [BMIM] [Br], $95 \%$ ethanol and $50 \%$ aceton in microwave at $80^{\circ} \mathrm{C}$, extraction power from 200 to $600 \mathrm{w}$ and extraction time from 20 to 60 min under different MAE conditions. MAE was performed on microwave apparatus using vessel system. After extraction, the vessel was allowed to cool at room temperature. The ethanol and aceton extracts were filtered and the solvents were removed using a rotary evaporator. While [BMIM] [Br] extract was filtered and then they were loaded onto an D-101macroporous resin column $(1.6 \times 60 \mathrm{~cm})$ (Figure 1$)$. The desorption conditions were as follows: wash by $1000 \mathrm{ml}$ of water, and eluted by $300 \mathrm{ml}$ of $90 \%$ ethanol, $1 \mathrm{ml} / \mathrm{min}$ of flow rate then disposed of ethanol by rotary evaporator. Dried extracts were kept refrigerated until use.

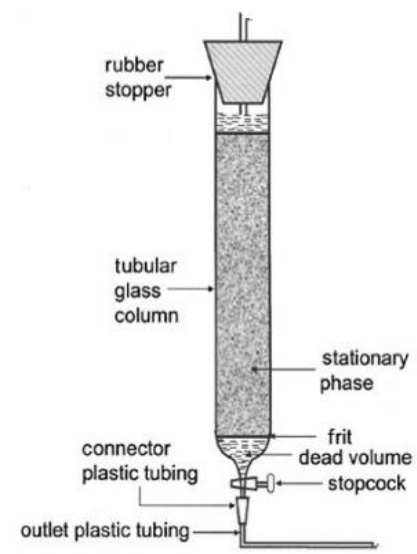

Figure 1. Removing the $[\mathrm{BMIM}][\mathrm{Br}]$ by $\mathrm{D}-101$ macroporous resin column

\subsection{Total Tannins (TT)}

The TT were determined by folin's and Ciocalteu method [6]. $0.1 \mathrm{ml}$ of the sample extract was added with $7.5 \mathrm{ml}$ of distilled water and adds $0.5 \mathrm{ml}$ of Folin Phenol reagent, $1 \mathrm{ml}$ of $35 \%$ sodium carbonate solution and diluted to $10 \mathrm{ml}$ with distilled water. The mixture was shaken well, kept at room temperature for $30 \mathrm{~min}$ and absorbance was measured at $\lambda 725$ [nm]. Blank was prepared with water instead of the sample. Using a five point calibration curve, the total tannins were determined by a comparison of the values obtained with the calibration curve of gallic acid from (Figure 2), total tannins values are expressed in terms of gallic acid equivalent (mg/g of dry extracted).

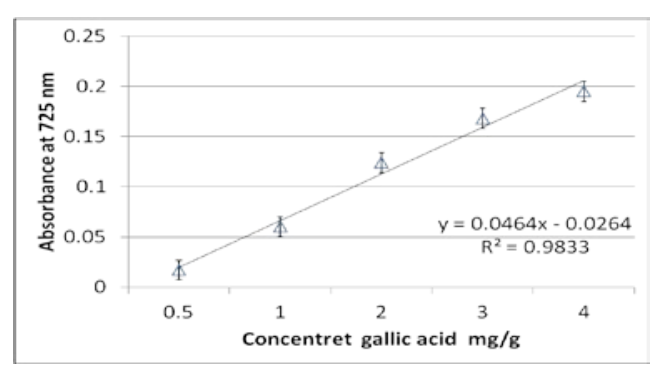

Figure 2. Calibration curve for gallic acid (mg/g of dry extracted)

\subsection{Determination of Antioxidant Activity Using DPPH Radical Scavenging Method}

In this assay, the antioxidant activity of plant extracts was evaluated by measuring the bleaching of the purplecolored ethanolic solution of 2,2-diphenyl-1picrylhydrazyl (DPPH) [7]. The antioxidant activity of six different concentrations $(0.2,0.1,0.05,0.02,0.01$, and $0.005) \mathrm{mg} / \mathrm{ml}$ of plant extracts was measured in terms of hydrogen donating or radical scavenging ability [8]. The mixtures were well shaken and kept at room temperature in the dark for 30 min., then absorbance (A) was measured at 517 (nm) using a spectrophotometer. Inhibition (I \%) of $\mathrm{DPPH}$ radical was calculated using the equation:

$$
\mathrm{I}(\%)=\mathrm{A}_{\text {blank }}-\mathrm{A}_{\text {sample }} / \mathrm{A}_{\text {blank }} \times 100
$$

\subsection{Single Factor Experiments}

Extraction of antioxidant using different solvents of [BMIM] [Br], ethanol and aceton, By fixing extraction time (40 min) and extraction temperature $\left(80^{\circ} \mathrm{C}\right)$ and 400 $\mathrm{w}$. The best solvent type was selected based on the highest value of antioxidant \% and TT (express as mg gallic acid equivalents/g dry weight).

The impact of extraction time on the antioxidant and TT were varied from 20, 40, and 60 minutes. $G$. japonicum extract was extracted using the solvent type and the extraction power chosen in single factor experiments. The extraction procedures were repeated by applying the solvent [BMIM] [Br], and extraction power $(400 \mathrm{w})$ at $80^{\circ} \mathrm{C}$. The best extraction time was chosen according to the highest values of antioxidant and TT.

Lastly, the extraction was executed by using the extraction time and solvent type selected in single factor experiments sections (1) and (2). G. japonicum were extracted at various extraction power which ranged from 200 to $600 \mathrm{w}$ at the optimum time determined. Based on the results of single factor experiment, the ranges of three factors (solvent type, extraction time and extraction power) were determined for RSM.

\subsection{Experiment Design of RSM}

A three level $(-1,0,+1)$ and three-factor $\left(\mathrm{X}_{1}, \mathrm{X}_{2}\right.$ and $\left.\mathrm{X}_{3}\right)$ in Table 1, those factors rotatable central design was 
utilized to examine the optimum combination of extraction variables based on the antioxidant activity and TT of G. japonicum.

The complete BBD design comprised of seventeen experiments with performed five central points at the centre of the design (Table 3 ) to allow a good estimation of pure error [9]. The design variables were the solvent type, $\mathrm{X}_{1}$, the extraction time, $\mathrm{X}_{2}$, and the extraction power, $\mathrm{X}_{3}$ (Table 1). All the experiments were performed in a random order.

Table 1. Variables and their levels for central composite design

\begin{tabular}{|c|c|c|c|c|c|}
\hline \multirow{2}{*}{ Independent variable } & \multirow{2}{*}{ Units } & \multirow{2}{*}{ Symbol } & \multicolumn{3}{|c|}{ Code levels } \\
\hline & & & -1 & 0 & +1 \\
\hline Solvents & Type & $\mathrm{X}_{1}$ & Aceton $50 \%$ & [BMIM][Br] (1.5 M ) & Ethanol 95\% \\
\hline Time & Min & $\mathrm{X}_{2}$ & 20 & 40 & 60 \\
\hline power & $\mathrm{W}$ & $\mathrm{X}_{3}$ & 200 & 400 & 600 \\
\hline
\end{tabular}

\subsection{Statistical Analysis}

The experimental results in single factor experiments were analyzed using calculated means and standard deviations of three simultaneous assays carried out. Statistical analysis (SPSS, 16) was applied to the data to determine differences $(\mathrm{P}<0.05)$ performed by ANOVA.

Multiple linear regression analysis was performed by the software Design-Expert (Version 6.0.10, Stat-Ease Inc., Minneapolis). Experimental data were fitted to the following second order polynomial model and regression coefficients were obtained. The generalized second-order polynomial model proposed for the response surface analysis was given as shown in equation :

$\mathrm{Y}=\beta_{0}+\sum \beta_{\mathrm{i}} \mathrm{x}_{\mathrm{i}}+\sum \beta_{\mathrm{i}} \mathrm{x}_{\mathrm{i}}^{2}+\sum \sum \beta_{\mathrm{ij}} \mathrm{x}_{\mathrm{i}} \mathrm{x}_{\mathrm{j}}$

Where $\beta_{0}$ was the value of the fitted response at the center point of the design, which was point $(0,0,0)$. $\beta_{0}, \beta_{\mathrm{i}}$, $\beta_{\mathrm{ii}}$, and $\beta_{\mathrm{ij}}$ were the constant, linear, quadratic and crossproduct regression terms, respectively. The quality of fit of the polynomial model was expressed by the coefficient of determination $\mathrm{R}^{2}$, and the statistical.

\section{Results and Discussion}

\subsection{Effect of Extraction Time, Solvents Type and of Power on the Antioxidant and TT}

In this study, the range of extraction time was designed based on the practical and economical aspects. Extraction time was another main parameter in the extraction procedure [10]. The decreased value antioxidant and TT in [BMIM] [Br] an increase time, this phenomenon could be explained that final equilibrium will be attained between the solution concentrations and solvent after a particular duration [11].
An increase in extraction time result in an increase in the extraction rate in all solvents, while the [BMIM] [Br] best solvent in antioxidant and TT. In general, the maximum concentration of antioxidant and TT was achieved at extraction time of $40 \mathrm{~min}$ at three solvents. After this point, the antioxidant and TT were decrease. As shown in Table 2 the highest value of antioxidant and TT for extraction time was at 40 minutes accompanied by a decrease at 60 minutes using [BMIM] [Br] as a solvent. There was decreased value antioxidant and TT in [BMIM] $[\mathrm{Br}]$ an increase time to $93.0 \% \pm 0.34$ and $2.6 \pm 0.27 \mathrm{mg} / \mathrm{g}$ respectively at $60 \mathrm{~min}$.

It was found out that prolonged extraction time lead to more exposure to oxygen and thus increase the chances for occurrence of oxidation [12,13]. Reduction of antioxidant and TT in extract with longer extraction time could also be caused by the endogenous enzymes in plant tissues [14]. Hence, an excessive extraction time was not useful to extract more antioxidants and TT [15]. Furthermore, prolonged extraction process might lead to oxidation due to light or oxygen exposure. However, there was no difference in extraction of free radical scavenging (antioxidant) and TT when compared to shorter time. Time does have a significant effect on extraction of TT as shown in Table 2. It was obvious that a shorter time will extract the same amount of TT extracts as longer time while saving cost. Also the extraction operation are different depending on the type of solvent and solvent polarity.

Table 2. showed the after 40 minutes extraction time there was decrease in antioxidant activity and TT for all solvents used, where the best solvent was [BMIM] [Br], followed by aceton than ethanol $(94.14 \pm 0.77,92.6 \pm 0.43$ and $91.5 \pm 0.27) \%(2.66 \pm 0.18,2.28 \pm 0.56$ and $2.11 \pm$ $0.46) \mathrm{mg} / \mathrm{g}$, respectively.

Table 2. Effect of the extraction time, solvent type and power on the (a) antioxidant activity and (b) TT from G. japonicum

\begin{tabular}{|c|c|c|c|c|c|c|c|c|c|c|c|c|c|}
\hline \multirow{2}{*}{\multicolumn{2}{|c|}{ Treatments }} & \multicolumn{3}{|c|}{$\mathrm{DPPH}$} & \multicolumn{3}{|c|}{$\mathrm{TT}$} & \multicolumn{3}{|c|}{$\mathrm{DPPH}$} & \multicolumn{3}{|c|}{$\mathrm{TT}$} \\
\hline & & \multirow{2}{*}{$\begin{array}{c}\text { aceton } \\
89.92\end{array}$} & \multirow{2}{*}{$\begin{array}{c}\begin{array}{c}\text { BMIM] } \\
{[\mathrm{Br}]}\end{array} \\
91.52\end{array}$} & \multirow{2}{*}{$\begin{array}{c}\text { ethanol } \\
87.59\end{array}$} & \multirow{2}{*}{$\frac{\text { aceton }}{2.2}$} & \multirow{2}{*}{$\begin{array}{c}\begin{array}{c}\text { [BMIM] } \\
{[\mathrm{Br}]}\end{array} \\
2.4\end{array}$} & \multirow{2}{*}{ 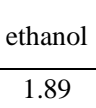 } & \multirow{2}{*}{$\begin{array}{c}20 \\
\min \\
-\end{array}$} & \multirow{2}{*}{$\begin{array}{c}40 \\
\min \end{array}$} & \multirow{2}{*}{$\begin{array}{c}60 \\
\text { min } \\
-\end{array}$} & \multirow{2}{*}{$\begin{array}{c}20 \\
\min \\
-\end{array}$} & \multirow{2}{*}{$\begin{array}{c}40 \\
\min \end{array}$} & \multirow{2}{*}{$\begin{array}{c}60 \\
\min \\
-\end{array}$} \\
\hline * & $20 \mathrm{~min}$ & & & & & & & & & & & & \\
\hline \multirow{2}{*}{$\begin{array}{l}\text { Extraction } \\
\text { time }\end{array}$} & $40 \mathrm{~min}$ & 91.6 & 93.14 & 89.5 & 2.28 & 2.66 & 2.11 & - & - & - & - & - & - \\
\hline & $60 \mathrm{~min}$ & 91.31 & 93 & 89.3 & 2.26 & 2.6 & 2.04 & - & - & - & - & - & - \\
\hline \multirow{3}{*}{$\begin{array}{c}* * * \\
\text { Solvent type }\end{array}$} & aceton & - & - & - & - & - & - & 90.92 & 92.9 & 91.3 & 2.2 & 2.28 & 2.26 \\
\hline & $\begin{array}{c}\text { [BMIM] } \\
{[\mathrm{Br}]}\end{array}$ & - & - & - & - & - & - & 92.52 & 94.14 & 94 & 2.4 & 2.66 & 2.6 \\
\hline & ethanol & - & - & - & - & - & - & 89.59 & 91.5 & 91.3 & 1.89 & 2.11 & 2.04 \\
\hline \multirow{3}{*}{$\begin{array}{c}* * * \\
\text { Power }\end{array}$} & $200 \mathrm{w}$ & 90.21 & 91.41 & 87.22 & 2.17 & 2.44 & 1.92 & - & - & - & - & - & - \\
\hline & $400 \mathrm{w}$ & 90.6 & 91.14 & 88.5 & 2.28 & 2.66 & 2.19 & - & - & - & - & - & - \\
\hline & $600 \mathrm{w}$ & 90.61 & 91.8 & 88.31 & 2.23 & 2.59 & 2.09 & - & - & - & - & - & - \\
\hline
\end{tabular}

* Effect of the extraction time on the (a) (a) antioxidant activity and (b) TT from G. japonicum at power $400 \mathrm{w}$ and temperature $80^{\circ} \mathrm{C}$

** Effect of the solvent type on the (a) antioxidant activity and (b) TT from $G$. japonicum at power $400 \mathrm{w}$ and temperature $80^{\circ} \mathrm{C}$

*** Effect of the power on the antioxidant activity and (b) TT from G. japonicum at time 40 min and temperature $80^{\circ} \mathrm{C}$ 
Increased in power resulted enhanced compounds solubility, faster diffusion rate, and increased mass transfer. However, it was noted that increasing the power beyond certain values may promote possible concurrent decomposition of compounds which were already mobilized at lower power or even the breakdown of some compounds that were still in the plant matrix. Additionally, high power may encourage solvent loss through vaporization and increase the cost for extraction process from the industrialization point of view. Therefore, moderate extraction power of 200, 400 and $600 \mathrm{w}$ were chosen as the lower, middle and upper levels, respectively, to be applied in RSM optimization.

There was high the values of antioxidant and TT even $400 \mathrm{w}$ below which there was a decrease in values after this power in the three solvents under study. As the value of antioxidant $93.14 \pm \%$ and TT $2.66 \pm \mathrm{mg}$ GAE/g at power $400 \mathrm{w}$ in [BMIM] [Br], then decreased to $91.8 \pm \%$ and $2.592 .66 \pm \mathrm{mg} \mathrm{GAE} / \mathrm{g}$ at power $600 \mathrm{w}$, respectively Table 2.

\subsection{Response Surface Methodology (RSM) Experiments}

Response surface methodology (RSM) is an effective tool for optimizing the process. The basic principle behind response surface methodology (RSM) analysis is to relate the observed value (dependent variables) to process parameters (independent variables) using statistical methods, yielding a multivariate regression equation, often of second-order. RSM uses an experimental design such as the box- Behnken design (BBD) to fit a model by least squares technique. As revealed by the diagnostic checking provided by an analysis of variance (ANOVA) and residual plots, contour plots can be usefully employed to study the response surface and locate the optimum [16].

Therefore, the results showed that the experimental model was adequate due to no significant lack of fit and satisfactory levels of $R^{2}$. The $R^{2}$ value of the dependent variables was more of 0.80 , indicating that a high proportion of variability was explained by the data [17].

Table 3. Operating parameters as well as the experimental and predicted values of extraction rate, antioxidant, TT and Triterpenes of G. japonicum for different setups of experimental design

\begin{tabular}{|c|c|c|c|c|c|c|c|c|}
\hline \multicolumn{4}{|c|}{ Independent variables } & \multirow{2}{*}{\multicolumn{3}{|c|}{ Uncoded variables }} & \multirow{3}{*}{$\begin{array}{c}\text { Analysis } \\
\text { TT mg/g extract }\end{array}$} & \multirow{3}{*}{ DPPH \% } \\
\hline \multicolumn{4}{|c|}{ Coded variables } & & & & & \\
\hline Treatment & $\mathrm{X}_{1}$ & $\mathrm{X}_{2}$ & $\mathrm{X}_{3}$ & Solvents & Time & Power & & \\
\hline 1 & 0 & -1 & -1 & [BMIM] [Br] & 20 & 200 & 2.28 & 90.87 \\
\hline 2 & 0 & 0 & 0 & [BMIM] [Br] & 40 & 400 & 2.66 & 93.14 \\
\hline 3 & 1 & -1 & 0 & ethanol & 20 & 400 & 1.89 & 87.59 \\
\hline 4 & 0 & -1 & 1 & [BMIM] [Br] & 20 & 600 & 2.20 & 91.11 \\
\hline 5 & -1 & 1 & 0 & aceton & 60 & 400 & 2.26 & 91.31 \\
\hline 6 & 0 & 1 & -1 & [BMIM] [Br] & 60 & 200 & 2.34 & 92.36 \\
\hline 7 & 1 & 1 & 0 & ethanol & 60 & 400 & 2.04 & 89.30 \\
\hline 8 & 0 & 0 & 0 & [BMIM] [Br] & 40 & 400 & 2.61 & 92.9 \\
\hline 9 & 0 & 0 & 0 & [BMIM] [Br] & 40 & 400 & 2.55 & 92.83 \\
\hline 10 & 0 & 1 & 1 & [BMIM] [Br] & 60 & 600 & 2.06 & 91.31 \\
\hline 11 & -1 & -1 & 0 & aceton & 20 & 400 & 2.20 & 89.92 \\
\hline 12 & 0 & 0 & 0 & [BMIM] [Br] & 40 & 400 & 2.59 & 92.8 \\
\hline 13 & -1 & 0 & -1 & aceton & 40 & 200 & 2.17 & 90.21 \\
\hline 14 & -1 & 0 & 1 & aceton & 40 & 600 & 2.23 & 90.61 \\
\hline 15 & 1 & 0 & -1 & ethanol & 40 & 200 & 1.86 & 87.22 \\
\hline 16 & 1 & 0 & 1 & ethanol & 40 & 600 & 1.92 & 88.31 \\
\hline 17 & 0 & 0 & 0 & [BMIM] [Br] & 40 & 400 & 2.52 & 92.88 \\
\hline
\end{tabular}

\subsection{Effect of Process Variables on Antioxidant}

The results of analysis of variance (ANOVA) showed in Table 4 the effect of process variables on antioxidant of extracts was highly significant $(\mathrm{p}<0.0001)$ with $\mathrm{R}^{2}$-value of 0.8867 and adjusted- $\mathrm{R}^{2}$ value of 0.8125 . The predicted model obtained for $\mathrm{Y}$ is given below:

$\mathrm{Y}=93.11 \quad-0.58 \quad \mathrm{X}_{1}+0.35 \quad \mathrm{X}_{2}+0.21 \quad \mathrm{X}_{3}+0.33 \quad \mathrm{X}_{1} \times$ $\mathrm{X}_{2}+0.17 \mathrm{X}_{1} \times \mathrm{X}_{3}+0.43 \mathrm{X}_{2} \times \mathrm{X}_{3}-1.70 \mathrm{X}_{1}^{2}-0.63 \mathrm{X}_{2}^{2}+$ $0.82 \mathrm{X}_{3}^{2}$

$\mathrm{X}_{1}, \mathrm{X}_{2}$ and $\mathrm{X}_{3}$ in this equation express solvent type, extraction time and microwave power, respectively.

The effect of solvent type, extraction time and microwave power on antioxidant is shown in Figure 3 (a, $\mathrm{b}$ and $\mathrm{c}$ ). It was noted that high antioxidant were in solvents ([BMIM] [Br], aceton and ethanol), respectively, Figure 3 (a). The antioxidant depended upon extraction time and microwave power, which resulted in a curvilinear increase until extraction time $40 \mathrm{~min}$ and microwave output power $400 \mathrm{w}$, and then to decreased in the antioxidant Figure 3 (b). Also it was found that effect of extraction time and microwave power on antioxidant was not high Figure 3 (c).

Table 4. ANOVA for the fitted model. for antioxidant

\begin{tabular}{cccccc}
\hline Source & $\begin{array}{c}\text { Sum of } \\
\text { squares }\end{array}$ & df & $\begin{array}{c}\text { Mean } \\
\text { square }\end{array}$ & $\begin{array}{c}\text { F- } \\
\text { value }\end{array}$ & $\begin{array}{c}\text { P-value } \\
\text { Prob>F }\end{array}$ \\
\hline Model & 23.48 & 9 & 2.61 & 2.87 & 0.0893 \\
X1 & 2.68 & 1 & 2.68 & 2.95 & 0.1298 \\
X2 & 0.97 & 1 & 0.97 & 1.07 & 0.3354 \\
X3 & 0.35 & 1 & 0.35 & 0.39 & 0.5532 \\
X1X2 & 0.44 & 1 & 0.44 & 0.48 & 0.5112 \\
X1X3 & 0.12 & 1 & 0.12 & 0.13 & 0.7282 \\
X2X3 & 0.73 & 1 & 0.73 & 0.80 & 0.3998 \\
X $_{1}^{2}$ & 12.20 & 1 & 12.20 & 13.42 & 0.0080 \\
$\mathrm{X}_{2}^{2}$ & 1.66 & 1 & 1.66 & 1.82 & 0.2190 \\
X3 & 2.83 & 1 & 2.83 & 3.11 & 0.1211 \\
Residual & 6.37 & 7 & 0.91 & & \\
Lack of fit & 0.94 & 3 & 0.31 & 0.23 & 0.8717 \\
Pure error & 5.43 & 4 & 1.36 & & \\
Cor total & 29.85 & 16 & & & \\
$\mathrm{R}^{2}$-value & & & 0.8867 & & \\
$\mathrm{R}^{2}$ value & & & 0.8125 & & \\
adjusted & & &
\end{tabular}



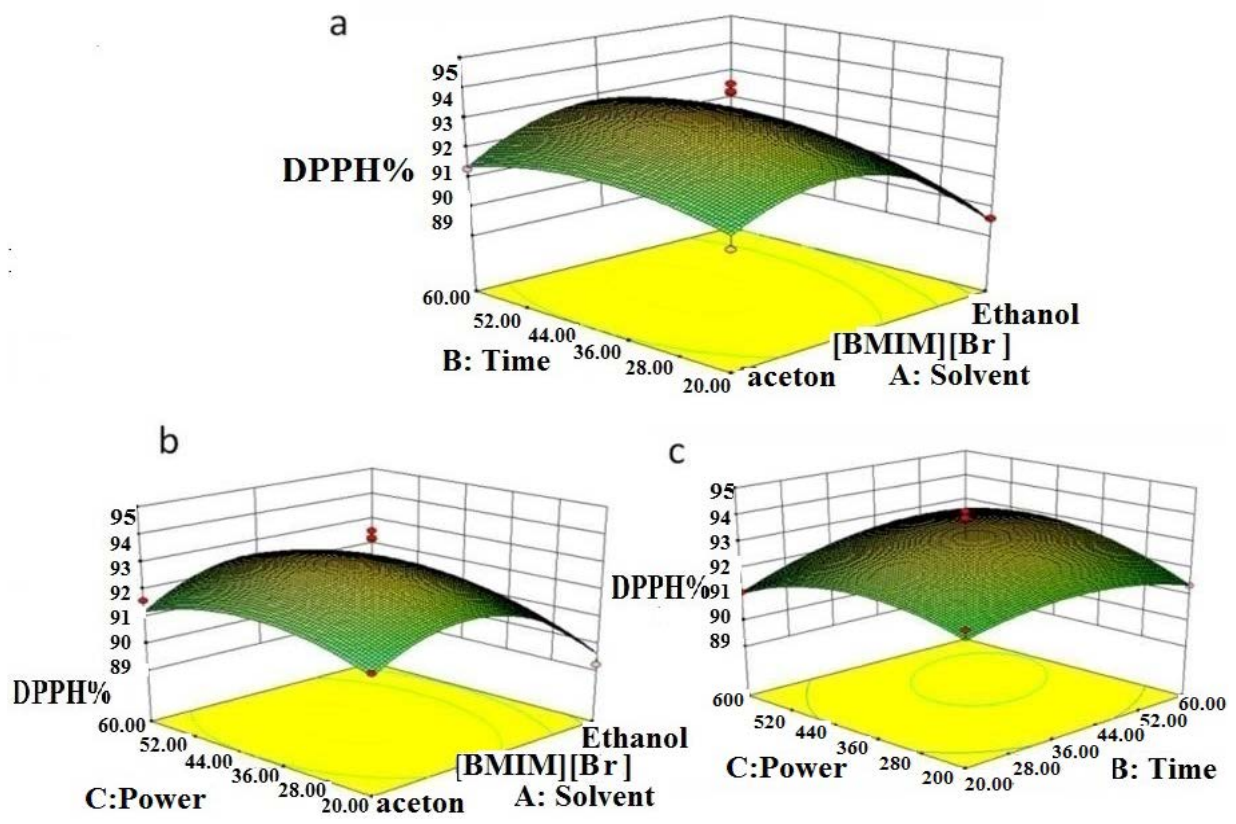

Figure 3. Response surface plot corresponding to (antioxidant) of G. japonicum of (a) solvent type and extraction time; (b) solvent type and power; and (c) extraction time and power. The value of the missing independent variable in each plot was kept at the middle level

\subsection{Effect of Process Variables on TT}

The Analysis of Variance (AVONA) of TT is presented in Table 5, using the designed experimental data (Table 3), the polynomial model for the TT was regressed and shown as below:

$\mathrm{Y}=2.59-0.14 \mathrm{X}_{1}+0.016 \mathrm{X}_{2}-0.030 \mathrm{X}_{3}+0.023 \mathrm{X}_{1} \times$ $\mathrm{X}_{2}+0 . .000 \mathrm{X}_{1} \times \mathrm{X}_{3}-0.050 \mathrm{X}_{2} \times \mathrm{X}_{3}-0.33 \mathrm{X}_{1}^{2}-0.16 \mathrm{X}_{2}^{2}-$ $0.21 \mathrm{X}_{3}^{2}$

$\mathrm{X}_{1}, \mathrm{X}_{2}$ and $\mathrm{X}_{3}$ in this equation express solvent type, extraction time and microwave power, respectively. Table 5 showed in the results of analysis of variance (ANOVA) the effect of process variables on TT of extracts was highly significant $(\mathrm{p}<0.0008)$ with $\mathrm{R}^{2}$-value of 0.9512 and adjusted- $\mathrm{R}^{2}$ value of 0.8885 . The estimated stationary point was represented as a maximum point. Thus, it can be concluded that the model was adequate to represent the relationship between the response and the independent variables.

The results of multiple regression showed that the TT was significantly affected by the interaction term of solvents type, extraction time and microwave power. These results [BMIM] [Br] were much higher than those of ethanol and aceton extraction (Table 3).

The contents of [BMIM] [Br] extraction from TT were much higher than those of aceton and ethanol extraction (Figure $4 \mathrm{a}$ and $\mathrm{b}$ ). Also the response curves of extraction time and microwave power were comparatively smooth (Figure c), indicating the decrease of the TT when microwave power changed in the range from 200 to $600 \mathrm{w}$, and there was the similar result TT when changing of extraction time from 20 to $60 \mathrm{~min}$ (Figure $4 \mathrm{a}$ and b).
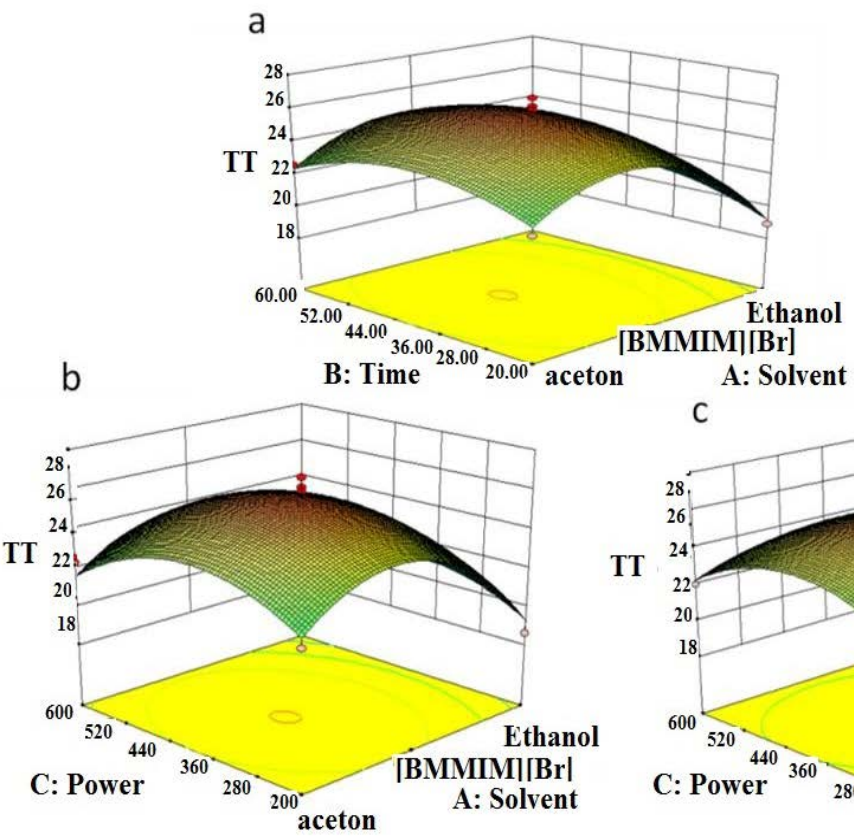

C

TT

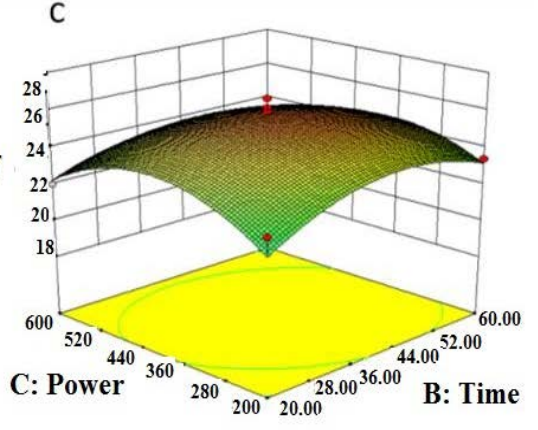

Figure 4. Response surface plot corresponding to (TT) of G. japonicum of (a) solvent type and extraction time; (b) solvent type and power; and (c) extraction time and power. The value of the missing independent variable in each plot was kept at the middle level 
Table 5. ANOVA for the fitted model. for TT

\begin{tabular}{cccccc}
\hline Source & $\begin{array}{c}\text { Sum of } \\
\text { squares }\end{array}$ & df & $\begin{array}{c}\text { Mean } \\
\text { square }\end{array}$ & $\begin{array}{c}\text { F- } \\
\text { value }\end{array}$ & $\begin{array}{c}\text { P-value } \\
\text { Prob }>\text { F }\end{array}$ \\
\hline Model & 1.01 & 9 & 0.11 & 15.17 & 0.0008 \\
X1 & 0.17 & 1 & 0.17 & 22.23 & 0.0022 \\
X2 & 2.113 & 1 & 2.113 & 0.28 & 0.6105 \\
X3 & 7.200 & 1 & 7.200 & 0.97 & 0.3579 \\
X1X2 & 2.025 & 1 & 2.025 & 0.27 & 0.6179 \\
X1X3 & 0.00 & 1 & 0.00 & 0.00 & 1.0000 \\
X2X3 & 0.010 & 1 & 0.010 & 1.34 & 0.2842 \\
$\mathrm{X}_{1}^{2}$ & 0.46 & 1 & 0.46 & 62.33 & 0.0001 \\
$\mathrm{X}_{2}^{2}$ & 0.10 & 1 & 0.10 & 13.91 & 0.0074 \\
X3 & 0.18 & 1 & 0.18 & 24.80 & 0.0016 \\
Residual & 0.052 & 7 & 7.44 & & \\
Lack of fit & 0.040 & 3 & 0.013 & 4.59 & 0.0876 \\
Pure error & 0.012 & 4 & 2.93 & & \\
Cor total & 1.07 & 16 & & & \\
$\mathrm{R}^{2}$-value & & & 0.9512 & & \\
$\mathrm{R}^{2}$ value - & & & 0.8885 & & \\
adjusted & & & & \\
\hline
\end{tabular}

There is a strong correlation between TT and antioxidant activity in Table 3 . These findings suggest that TT were a good predictor of in vitro antioxidant activity. The response surface plots showed the relationship between the TT and solvent type, extraction time and microwave power in Figure 4 ( $a$, and b).

\subsection{The Optimum Condition of Antioxidant and TT}

According to the desired goals, and in order to verify the predictive capability of the model, optimum conditions were established by RSM and comparisons between the predicted results and the practical values were done by experimental rechecking using those presumed optimal conditions. Table 6 presented the optimum conditions for (antioxidant and TT ) and its predicted and experimental value.

The optimal extraction conditions of antioxidant and TT from $G$. japonicum extracts and independent variables, and the predicted and experimental values of the responses also are presented as follows: solvents type [BMIM] $\mathrm{Br}$, extraction time $36.89 \mathrm{~min}$ and microwave power $437.07 \mathrm{w}$. Under these optimal conditions, the model predicted a maximum response of $92.24 \%$ and $2.44 \mathrm{mg} / \mathrm{g}$ for antioxidant and TT, respectively from G. japonicum extracts. Mean values of $95.1 \pm 3.18$ and $3.01 \pm 1.44$ were acquired from real experiments, respectively.

The optimum conditions for extraction for larger antioxidant rate when designing individually analysis from G. japonicum extracts and independent variables, and the predicted and experimental values of the responses also are presented as follows: solvents type, [BMIM] Br; extraction time, $46.20 \mathrm{~min}$ and microwave power, 439.24 w. Under these optimal conditions, the model predicted a maximum response of $93.22 \%$ for antioxidant rate, a mean value of $95.1 \pm 3.18 \%$ was acquired from real experiments.

While TT was as follows: solvents type [BMIM] Br, extraction time $40.96 \mathrm{~min}$ and microwave power $384.49 \mathrm{w}$, the model predicted a maximum response of $2.6 \%$ for antioxidant, a mean value of $3.01 \pm 1.44 \%$ was acquired from real experiments.

Table 6. The optimum condition of antioxidant and TT

\begin{tabular}{|c|c|c|c|c|c|}
\hline & Solvents & Extraction time (min) & Microwave power (W) & Predicted & Experimental \\
\hline Antioxidant \% & [BMIM] [Br] & 46.20 & 439.24 & 93.22 & $95.1 \pm 3.18$ \\
\hline Tannin mg/g & [BMIM] [Br] & 40.96 & 384.49 & 2.60 & $3.01 \pm 1.44$ \\
\hline $\begin{array}{c}\text { Antioxidant \% } \\
\text { Tannin mg/g }\end{array}$ & [BMIM] [Br] & 36.89 & 437.07 & $\begin{array}{c}92.24 \\
2.44\end{array}$ & $\begin{array}{l}91.5 \pm 2.12 \\
2.72 \pm 2.34\end{array}$ \\
\hline
\end{tabular}

The experimental results were very close to the predicted point (Table 6). This implied that there was a high fit degree between the values observed in experiment and the value predicted from the regression model. Hence, the response surface modeling could be applied effectively to predict extraction of extraction rate, antioxidant and TT from $G$. japonicum

\section{Conclusion}

This study demonstrates that it is essential to optimize systematically the extraction solvent composition, extraction time and power for accurate of G. japonicum. Also the difference in the time and power you do not have an effect is high compared with solvents. Our results showed that [BMIM] [Br] solvent are more efficient in the extraction of antioxidant and TT compare with ethanol and aceton solvents. This study confirmed that the [BMIM] [Br] (1.5), extraction time $36.89 \mathrm{~min}$ and extraction power $437.07 \mathrm{w}$ were the most efficient for extraction of antioxidant and TT.

\section{Acknowledgment}

The study was supported by the 12th Five-Year Plan for Science and Technology Development (No.
2012BAD33B05), Chinese Nature Science Foundation (21403601 and 31201805), Fundamental Research Funds for the Central Universities (JUSRP111A36, JUSRP1052), and Priority Academic Program Development of Jiangsu Higher Education Institutions.

\section{Reference}

[1] Masahiko K, Tomomi S, Wataru W, Kimiyasu S. Development of New Antiviral Agents from Natural Products. Antimicrobial Agents Journal, 2. 49-57. 2010.

[2] Xiangrong C, Jiangjiang Q, Qi Z, Shoude Z, Fei Z, Shikai Y, Huizi J, Weidong Z. Taraxasterane-Type Triterpene and Neolignans from Geum japonicum Thunb. var. chinense F. Bolle. Planta Med, 77. 2061-2065. 2011.

[3] Hongwei Liu, Jiankuan Li, Wenhua Zhao, Li Bao, Xiaohong Song, Ying Xia, Xue Wang, Chao Zhang, Xiaozhu Wang, Xinsheng Yao and Ming Li. Fatty Acid Synthase Inhibitors from Geum japonicumThunb. var. chinense. Chemistry \& Biodiversity, 6. 402-410. 2009

[4] Hong-Xi X, Dong-SM, Hui D, Paul Pui-HB. A New Anti-HIV Triterpene from Geum japonicum. Chem. Pharm. Bull, 48 (9). 1367-1369. 2000.

[5] Prasad KN, Hassan FA, Yang B, Kong KB, Raman RN, Azlan A, Ismail A. Response surface optimization for the extraction of phenolic compounds and antioxidant capacities from Mangifera pajang Kosterm. peels. Food Chem., 128. 1121-1127. 2011.

[6] Tamilselvi P, Krishnamoorthy R, Dhamotharan P, Arumugam E, Sagadevan. Analysis of total phenols, total tannins and screening of phytocomponents in Indigofera aspalathoides (Shivanar Vembu) 
Vahl EX DC. Journal of Chemical and Pharmaceutical Research, 4. 3259-3262. 2012.

[7] Burits M, Bucar F. Antioxidant activity of Nigella sativa essential oils. Phytotherapy Research, 14. 323-328. 2000.

[8] Brand WW, Cuvelier ME, Berset C. Use of free radical method to evaluate antioxidant activity. Lebensmittel Wissenschaft and Technologie, 28. 25-30. 1995.

[9] Sin HN, Yusof S, Hamid NSA. Optimization of hot water extraction for sapodilla juice using response surface methodology. J. Food Eng, 74. 352-358. 2006

[10] Lapornik B, Prosek M, Wondra AG. Comparison of extracts prepared from plant by-products using different solvents and extraction time. Journal of Food Engineering, 71. 214-222. 2005

[11] Pinelo M, Sineiro J, Núñez MJ. Mass transfer during continuous solid-liquid extraction of antioxidants from grape byproducts. Journal of Food Engineering 2006; 77 (1): 57-63.

[12] Naczk M, Shahidi F.. Extraction and analysis of phenolics in food. J. Chormatogr. A 1054. (1-2). 95-111. 2004
[13] Chirinos R, Rogez H, Campos D, Pedreschi R, Larondelle Y. Optimization of extraction conditions of antioxidant phenolic compounds from mashua (Tropaeolum tuberosum Ruíz and Pavón) tubers. Separation and Purification Technology, 55 (2). 217-225. 2007

[14] Kuljarachanan T, Devahastin S, Chiewchan N. Evolution of antioxidant compounds in lime residues during drying. Food Chemistry, 113 (4). 944-949. 2009

[15] Silva EM, Rogez H, Larondelle Y. Optimization of extraction of phenolics from Inga edulis leaves using response surface methodology. Journal of Separation and Purification Technology, 55. 381-387. 2007.

[16] Rustom IYS, López-leiva MH, Nair BM. Optimization of extraction of peanut proteins with water by response surface methodology. J. Food Sci., 56 (6). 160-163. 1991.

[17] Varnalis AI, Brenan JG, Macdougall DB, Gilmour SG. Optimization of high temperature puffing of potato cubes using response surface methodology. J Food Eng, 61. 153-163. 2004. 